гической защиты растений, Всероссийский научно-исследовательский институт картофельного хозяйства имени А.Г. Лорха. Россия.

140051, Московская обл., Любереикий $p$-н, пос. Красково, ул. Лорха, 23, литер В. Тел.: 89165273295.

Ключевъе слова: картофель; биопрепараты; фунгицицы; болезни; эффективность.

\title{
THE EFFECTIVENESS OF A NEW BIOLOGICAL PRODUCT KARTOFIN ON THE BASIS OF BACILLUS SUBTILIS IN THE CULTIVATION OF POTATOES
}

Derevyagina Marina Konstantinovna, Candidate of Biological Sciences, Leading Researcher, All-Russian Research Institute of Potato Farming named after A.G. Lorch. Russia.

Vasilyeva Svetlana Viktorovna, Candidate of Agricultural Sciences, Leading Researcher, All-Russian Research Institute of Potato Farming named after A.G. Lorch. Russia.

Belov Grigory Leonidovich, Candidate of Biological Sciences, Senior Researcher, All-Russian Research Institute of Potato Farming named after A.G. Lorch. Russia.

Zeyruk Vladimir Nikolaevich, Doctor of Agricultural Sciences, Head of the laboratory of plant protection, All-Russian Research Institute of Potato Farming named after A.G. Lorch. Russia.

Novikova Irina Igorevna, Doctor of Biological Sciences, Leading Researcher of the laboratory of microbiological plant protection, All-Russian Research Institute of Potato Farming named after A.G. Lorch. Russia. ficiency.

Keywords: potatoes; biopreparations; fungicides; diseases; ef-
It is shown the efficiency of the application of preparative forms (dry and liquid) of Kartofin during the growing season 2016-2018 years against major diseases of potatoes and the impact on the growth and development of culture. Biopreparation possesses high fungistatic effect, protecting potato plants against rhizoctonia disease, potato blight and late blight under field conditions and tubers of the new crop from dry rot. In years of low and moderate disease development, the effectiveness of the studied Potato biopreparation on the Sante variety was at the level of the reference chemical variant, equally reducing the distribution and degree of disease development. In the years of epiphytotic disease development fungistatic effect of the biopreparation was inferior in efficiency to chemical fungicides, but had a significant protective effect compared to the control, reducing the distribution of rhizoctonia disease by $22.5 \%$, potato blightby $20.7 \%$, late blight by $12.8 \%$ on average. The results of tuberous analyses after harvesting showed a decrease in the percentage of tuber damage by dry rot in variants with Kartofin (1.7 and 1.4\%). The yield of the standard potatoes after application of Kartofin was slightly higher than in the control - by 5.1-7.7\%.

\section{ЭКСПРЕСС-МЕТОД УЧЕТА И ПРОГНОЗА ЗЛАТОГУЗКИ (EUPROKTIS CHRISORRHOEA L.) В ЛЕСНЫХ И САДОВЫХ НАСАЖДЕНИЯХ}

\author{
ДУБРОВИН Владимир Викторович, Саратовский государственный аграрный университет \\ имени Н.И. Вавилова
}

МЛАДЕНЦЕВ Виктор Евгеньевич, Саратовский государственный аграрный университет имени Н.И. Вавилова

Изучены биологические особенности златогузки, опасного вредителя многих древесных и садовых насаждений, для разработки экспресс-метода получения достаточно быстрых и достоверных данных учета и прогноза. Приведена сравнительная характеристика существующих методик учета златогузки как в лесных насаждениях, так и в садовых. Установлено, ито принятые в производство методы учета лишены статистического обоснования и данных по величине и количеству учетных единиц. Показано, что наиболее информативный показатель для получения данных о заселенности насаждений - развитие фитофага на фазе гусеницы в зимующих гнездах. Массовые учеты зимующих гнезд с одновременной оценкой численности находящихся в них гусениц и степени объедания насаждений позволили выявить зависимость между этими величинами. Разработаны таблицы для быстрого определения необходимого объема выборки с тремя уровнями точности. Разработана таблица, устанавливающая численность гусении, вредителя в зависимости от размера зимующих гнезд. Получена модель, позволяющая прогнозировать степень ожидаемого повреждения насаждений вредителем.

Введение. Среди многих листогрызущих насекомых златогузка является опасным фитофагом. Уничтожая листву, она наносит большой ущерб как лесным, так и плодовым насаждениям [3]. Для организации системы надзора за златогузкой важно использовать методику учета вредителя, позволяю2019

щую с наименьшими трудовыми затратами давать оценку заселенности насаждений, максимально соответствующую фактической [2]. Согласно анализу производственных нормативных материалов и инструкций по защите растений от вредных насекомых, существующие методы их учета лишены математического обоснования. Это обстоятельство затрудняет проводить оценку плотности популяций насекомого с заданной точностью учета, что ведет к ошибкам в определении действительной заселенности насаждений вредителем.

Кроме того, оптимизация учетных работ дает возможность повысить производительность труда при ведении мониторинга и получить достоверные популяционные данные, которые необходимы для прогноза и принятия решений о целесообразности проведения защитных мероприятий. Эффект планируемой защиты растений зависит 
от своевременного проведения мероприятий по выявлению и ликвидации очагов златогузки. Так, на основании существующего метода учета златогузки проводится подсчет в процентах 10 учетных плодовых деревьев [4]. Недостатками метода являются статистическая необоснованность объема выборки, что ведет к закономерным ошибкам в определении действительной заселенности; отсутствие данных о размерах самих гнезд златогузки, т.к. от этого напрямую зависит количество находящихся в них гусениц. Данный способ является трудоемким и малодостоверным.

Известен также другой способ определения заселенности насаждений вредителем [6]. По этой методике для учета златогузки стационарный надзор и стационарные обследования следует проводить в более молодых лесных насаждениях. С каждой пробы необходимо брать по три гнезда (среднее, наиболее крупное и наиболее мелкое) и анализировать их на пораженность гусениц паразитами и болезнями в комнатных условиях. Согласно рекомендациям, указанным в книге [5], рекогносцировочный и стационарный надзор за златогузкой проводят поздней осенью по зимним гнездам. Количество гнезд на деревьях также подсчитывают визуально с земли.

Недостатками указанных способов является то, что, как показала практика, данные учета необходимо получать сразу в полевых условиях, а работа в комнатных условиях сопряжена с тратой дополнительного времени. При этом анализ гусениц и их вскрытие потребует специальных знаний. Кроме того, гусеницы имеют ядовитые волоски и при вскрытии гнезд обжигают слизистые оболочки, лицо, шею и руки. Дополнительно потребуется для исследователя применение индивидуальных средств защиты. Далее оценить предстоящую угрозу по трем гнездам старых насаждений невозможно, для них данный показатель угрозы явно будет занижен.

Цель данной работы - обоснование применения экспресс-метода учета и прогноза златогузки в лесных и садовых насаждениях для получения достаточно быстрых и достоверных данных заселенности вредителем.

методика исследований. Для получения данных, необходимых для разработки экспрессметода учета златогузки, были заложены пробные площади в лесных и садовых насаждениях Пензенской области [1]. Каждая проба включала в себя не менее 10 модельных деревьев с наличием зимующих гнезд вредителя. Учет гнезд проводили осенью, в период появления гнезд, с ушедшими на зимовку гусеницами (октябрь - ноябрь). Полученные с каждой пробной модели гнезда сортировали на крупные, средние и мелкие.

Далее производили подсчет находящихся в гнездах гусениц. Для разработки экспресс-метода был произведен анализ соответствия данных по числу гусениц в гнездах в природных условиях расчетным данным, полученным в лабораторных условиях. Расчет проводили путем измере- ния ширины гнезд (в сантиметрах) в наиболее широком месте с последующим определением их объема по длине окружности. Далее подсчитывали количество гусениц в гнездах и находили разницу между данными - расчетными и полученными в природных условиях. Кроме того, устанавливали смертность гусениц от выявленных факторов для последующего применения в расчетах.

В результате статистического анализа были получены таблицы для обоснованного учета и прогноза златогузки в лесных и садовых насаждениях.

Результатъ исследований. Предлагаемый экспресс-метод учета и прогноза златогузки в насаждениях заключается в следующем. Вначале необходимо определить требуемое количество деревьев для проведения учета гнезд златогузки. Как правило, гнезда располагаются на побегах с густо расположенными листьями. Для быстрого определения необходимого объема выборки с тремя уровнями точности используется статистически обоснованная табл. 1, составленная на основании уравнения:

$$
\mathrm{N}=t^{2} S^{2} / \bar{x}^{2} \varepsilon^{2},
$$

где $t$ - критерий Стьюдента; $S^{2}$ - дисперсия; $x^{2}-$ средняя численность; $\varepsilon$ - относительная точность учета.

Для использования табл. 1 вначале берется небольшая предварительная выборка (3-5 деревьев), определяется среднее число гнезд на этих деревьях. Затем определяется необходимый объем выборки (количество деревьев с гнездами) для установления действительной средней заселенности гнездами на исследуемом участке.

Например. По предварительной выборке во время учета (3-5 деревьев) среднее число гнезд оказалось равным 4. Чтобы определить действительную среднюю заселенность участка с точностью 10 \%, необходимо взять для учета 102 дерева, с точностью $20 \%$ - 26 деревьев, с точностью 30 \% - 11 деревьев. Точность учета 20 \% будет являться разумной гранью между трудозатратами и ценностью информации.

Далее, в зависимости от породы (садовая или лесная), где будет производиться подсчет гнезд, необходимо замерить длину окружности собранных гнезд в широком их основании с помощью мерной ленты (в сантиметрах). По табл. 2 устанавливается расчетное количество гусениц златогузки, которое может находиться в гнезде.

Предположим, в исследуемом насаждении было заложено 26 деревьев, чтобы обеспечить точность учета 20 \%, было проанализировано 70 гнезд златогузки. Устанавливаем количество находящихся в гнездах гусениц в зависимости от длины окружности гнезда (см. табл. 2). Находим средние значения. Если среднее значение длин окружности проанализированных гнезд составило 10,6 см, то ближайшее значение 10,5 см покажет 517 гусениц, находящихся в гнездах. Прибавляя к расчетному числу гусениц (517) поправочный коэффициент 
Определение средней численности гнезд златогузки с заданной точностью учета

\begin{tabular}{|c|c|c|c|}
\hline \multirow{2}{*}{$\begin{array}{c}\text { Средняя } \\
\text { чиенность } \\
\text { гнезд }\end{array}$} & \multicolumn{3}{|c|}{ Заданная точность учета } \\
\cline { 2 - 4 } наерево & Количество учетных единиц (деревьев) \\
\cline { 2 - 4 } & $10 \%$ & $20 \%$ & $30 \%$ \\
\hline 0,5 & 191 & 48 & 21 \\
\hline 1,0 & 140 & 35 & 16 \\
\hline 2,0 & 115 & 29 & 13 \\
\hline 3,0 & 107 & 27 & 12 \\
\hline 4,0 & 102 & 26 & 11 \\
\hline 5,0 & 99 & 25 & 10 \\
\hline 6,0 & 98 & 24 & 9 \\
\hline 7,0 & 97 & 23 & 8 \\
\hline 8,0 & 96 & 22 & 7 \\
\hline 9,0 & 95 & 21 & 6 \\
\hline 10,0 & 94 & 20 & 5 \\
\hline
\end{tabular}

равный 25 гусеницам, получаем фактический запас вредителя, ушедшего на зимовку, то есть 542 гусеницы. Полученные данные заносим в табл. 2 .

Чтобы узнать, какое количество гусениц следует ожидать весной следующего года после выхода из гнезд и оценить угрозу предстоящего объедания деревьев необходимо использовать табл. 3. Полученные данные фактического запаса следует умножить на коэффициент смертности гусениц 0,43 . По нашим данным, гусеницы, ушедшие на зимовку, находятся во 2-3-м возрасте, а коэффициент смертности от различных факторов (болезни, птицы) в этом возрастном интервале составляет 0,43 , или $43 \%$. Таким образом получаем $542 \cdot 0,43=$ $=233$ гусеницы, столько в среднем на данный участок насаждений появится из гнезд после зимовки.

Для расчета угрозы предстоящего поврежде-
Определение фактического запаса гусениц в гнездах после перезимовки

\begin{tabular}{|c|c|c|}
\hline $\begin{array}{c}\text { Фактический } \\
\text { запас гусениц в } \\
\text { гнездах } \\
\text { до зимовки }\end{array}$ & $\begin{array}{c}\text { Коэффициент } \\
\text { смертности } \\
\text { гусениц } \\
\text { во время } \\
\text { зимовки }\end{array}$ & $\begin{array}{c}\text { Фактический } \\
\text { запас гусениц } \\
\text { в гнездах после } \\
\text { перезимовки }\end{array}$ \\
\hline 542 & 0,43 & 233 \\
\hline
\end{tabular}

ния насаждений следует использовать следующее уравнение регрессии:

$$
y=7,400+0,098 x,
$$

где $y$ - степень ожидаемого повреждения насаждений от златогузки, \%; $x$ - численность гусениц на модельных ветвях. Ошибка модели для прогноза степени ожидаемого повреждения насаждений от златогузки составляет $m_{y}= \pm 7,7 \%$.

Если полученные данные по числу гусениц в гнездах после зимовки из табл. 3 вставить в уравнение (2), то таким образом рассчитаем в процентах угрозу объедания лесных или садовых насаждений, \%. Например, при подсчете гусениц в гнездах после зимовки оказалось в среднем 233 шт. на одно гнездо, предполагаемая угроза дефолиации крон по уравнению (2) составит 30 \%. Делая скидку на ошибку модели $\pm 7,7$ \%, можно утверждать, что угроза объедания крон деревьев будет колебаться в интервале 37-23\%. Угроза объедания насаждений 50 \% и выше может явиться критерием целесообразности проведения защитных мероприятий.

Заключение. Предложенный экспресс-метод учета и прогноза златогузки в насаждениях позволит получить достаточно быстрые и достоверные данные запаса вредителя в насаждениях, установить угрозу предстоящего их объедания и своевременно назначить защитные мероприятия.

Таблица 2

\section{Расчет фактического запаса гусениц златогузки в гнездах}

\begin{tabular}{|c|c|c|c|c|c|c|c|}
\hline $\begin{array}{c}\text { Вид } \\
\text { древесной } \\
\text { породы }\end{array}$ & $\begin{array}{l}\text { Длина ок- } \\
\text { ружности } \\
\text { гнезда, см }\end{array}$ & $\begin{array}{c}\text { Объем } \\
\text { гнезда, } \\
\text { см }^{3}\end{array}$ & $\begin{array}{c}\text { Расчетное } \\
\text { число } \\
\text { гусениц, на- } \\
\text { ходящихся в } \\
\text { гнезде, шт. }\end{array}$ & $\begin{array}{c}\text { Вид } \\
\text { древесной } \\
\text { породы }\end{array}$ & $\begin{array}{l}\text { Длина ок- } \\
\text { ружности } \\
\text { гнезда, см }\end{array}$ & $\begin{array}{c}\text { Объем } \\
\text { гнезда, } \\
\text { см }^{3}\end{array}$ & $\begin{array}{c}\text { Расчетное } \\
\text { число } \\
\text { гусениц, } \\
\text { находя- } \\
\text { щихся в } \\
\text { гнезде, шт. }\end{array}$ \\
\hline \multirow{17}{*}{$\begin{array}{c}\text { Лесная } \\
\text { или } \\
\text { садовая }\end{array}$} & 5,0 & 2,11 & 242 & \multirow{17}{*}{$\begin{array}{c}\text { Лесная } \\
\text { или } \\
\text { садовая }\end{array}$} & 13,5 & 41,54 & 667 \\
\hline & 5,5 & 2,81 & 267 & & 14,0 & 46,33 & 693 \\
\hline & 6,0 & 3,64 & 292 & & 14,5 & 51,47 & 717 \\
\hline & 6,5 & 4,64 & 317 & & 15,0 & 56,98 & 742 \\
\hline & 7,0 & 5,79 & 342 & & 15,5 & 62,87 & 767 \\
\hline & 7,5 & 7,12 & 367 & & 16,0 & 69,15 & 792 \\
\hline & 8,0 & 8,64 & 392 & & 16,5 & 75,84 & 817 \\
\hline & 8,5 & 10,37 & 417 & & 17,0 & 82,94 & 842 \\
\hline & 9,0 & 12,31 & 442 & & 17,5 & 90,48 & 867 \\
\hline & 9,5 & 14,48 & 467 & & 18,0 & 98,46 & 893 \\
\hline & 10,0 & 16,88 & 493 & & 18,5 & 106,89 & 917 \\
\hline & 10,5 & 19,54 & 517 & & 19,0 & 115,80 & 942 \\
\hline & 11,0 & 22,47 & 542 & & 19,5 & 125,18 & 967 \\
\hline & 11,5 & 25,68 & 567 & & 20,0 & 135,06 & 992 \\
\hline & 12,0 & 29,17 & 593 & & 20,5 & 145,45 & 1017 \\
\hline & 12,5 & 32,97 & 617 & & 21,0 & 156,35 & 1043 \\
\hline & 13,0 & 37,09 & 642 & & & & \\
\hline
\end{tabular}


Все это имеет большое научное и хозяйственное значение.

\section{СПИСОК ЛИТЕРАТУРЫ}

1. Доспехов Б.А. Методика полевого опыта. - М.: Колос, 1985. - 416 с.

2. Дубровин В.В. Организация защиты растений от вредных организмов. - Саратов, 2016. - 388 с.

3. Дубровин В.В.Совершенствование методов учета и прогноза в системе мониторинга за кольчатым коконопрядом (Malacosomaneus tria L.) в защите древесных растений // Аграрный научный журнал. - 2016. № 3. - С. 26-28.

4. Контроль за фитосанитарным состоянием посевов сельскохозяйственных культур в Российской Федерации / В.Т. Алехин [и др.]. - Воронеж, 1988. - 335 с.

5. Массовые хвое- и листогрызущие вредители леса / С.Г. Гамаюнов [и др.]. - Харьков, 1999. - 172 с.

6. Надзор, учет и прогноз массовых размножений хвое- и листогрызущих насекомых / А.И. Ильинский [и др.]. - М., 1965. - 524 с.

Дубровин Владимир Викторович, д-p биол. наук, проф. кафедры «Защита растений и плодоовощеводство», Саратовский государственный аграрный университет имени Н.И. Вавилова. Россия.

Младенцев Виктор Евгеньевич, аспирант кафедры «Защита растений и плодоовощеводство», Саратовский государственный аграрный университет имени Н.И. Вавилова. Россия.

410012, г. Саратов, Театральная пл., 1.

Тел.: (8452) 26-27-83.

Ключевые слова: златогузка; зимующие гнезда; экспресс-метод учета; прогноз.

\title{
EXPRESS METHOD OF ACCOUNTING AND FORECASTING BROWN-TAIL MOTH (EUPROKTIS CHRISORRHOEA L.) IN FOREST AND GARDEN PLANTATIONS
}

Dubrovin Vladimir Viktorovich, Doctor of Biological Sciences, Professor of the chair "Plant Protection and Horticulture" Saratov State Agrarian University named after N.I. Vavilov. Russia.

Mladentsev Viktor Evgenievich, Post-graduate Student of the chair "Plant Protection and Horticulture" Saratov State Agrarian University named after N.I. Vavilov. Russia.

Keywords: brown-tail moth; winter nests; express accounting method;forecast.

The biological peculiarities of brown-tail moth, a dangerous pest of many tree and garden plantings, were studied in order to develop a rapid method for obtaining sufficiently fast and reliable accounting and forecasting data. A comparative description of the existing methods of accounting of brown-tail moth in forest plantations and in garden ones has been carried out. It has been established that the accounting methods adopted in production are devoid of statistical justification and data on the size and number of accounting units. It is shown that the most informative indicator for obtaining data on the population of stands is the development of phytophage at the caterpillar phase in winter nests. Mass counts of winter nests with a simultaneous estimate of the number of caterpillars in them and the degree of nibbling of plantations made it possible to identify the relationship between these values. Tables for quick determination of the required sample size with three levels of accuracy are developed. A table establishing the number of pest larvae depending on the size of wintering nests has been developed. A model that allows predicting the degree of expected damage to plantings by a pest has been obtained.

удк632.754.1

\section{ВРЕДОНОСНОСТЬ ИМАГО И ЛИЧИНОК ПШЕНИЧНОГО ТРИПСА (HAPLOTHRIPS TRITICI KURD.),TEOPETИЧECKOE OБOCHOВAHИE И ПРАКТИЧЕСКАЯ РЕАЛИЗАЦИЯ МЕТОДИКИ ЕЕ ОПРЕДЕЛЕНИЯ}

\author{
ЕМЕЛЬЯНОВ Николай Архипович, Саратовский государственный аграрный университет \\ имени Н.И. Вавилова
}

ЕСЬКОВ Иван Дмитриевич, Саратовский государственный аграрный университет имени Н.И. Вавилова

КРИТСКАЯ Елена Евгеньевна, Саратовский государственный аграрный университет имени Н.И. Вавилова

Проанализированы известные методы определения вредоносности трипсов. Показана их недостаточная объективностъ. Предлагается новый подход в виде логической модели, которая определяет время, место, условия и последовательность проведения исследований по изучению вредоносности имаго и личинок трипса. Данный метод позволяет на одних и тех же изолированных модельных растениях определять суммарную вредоспособность имаго и личинок трипса и выделять показатели вредоспособности и вредоносности отдельных стадий фитофага. Показана практическая реализация логической модели, в результате чего установлена суммарная вредоспособность имаго и личинки трипса на яровой пшенице - 6,6 мг потеръ урожая с колоса. Впервъе показана вредоспособность имаго, составляющая 4,9 мг/особъ, и личинок1,71 мг/особъ, что в 2,86 раза менъие.

Введение. Пшеничный трипс (Haplothrips tritici Kurd.), размножаясь на посевах пшеницы, наносит значительный урон зерновому хозяйству. Личинки его питаются отдельными зерновками в колосьях пшеницы и снижают их абсолютный вес. Поврежденность зерна зависит от численности личинок и изменяется по разным данным от 19,6 до $73,7 \%$ [21] иот 35 до 90,6\% [11].В многочисленных 